\title{
Emergency nurses' experiences of caring for survivors of intimate partner violence
}

\section{Annatjie van der Wath}

M Cur RN

Lecturer

Department of Nursing Science, School of Health Care Sciences, University of Pretoria, South Africa

\section{Neltjie van Wyk}

PhD RN

Professor

Department of Nursing Science, School of Health Care Sciences, University of Pretoria, South Africa

\section{Elsie Janse van Rensburg \\ D Cur RN}

Senior Lecturer

Department of Nursing Science, School of Health Care Sciences, University of Pretoria, South Africa 


\section{ABSTRACT}

Aim. To report a study of emergency nurses' experiences of caring for survivors of intimate partner violence.

Background. Emergency nurses have the opportunity to intervene during the period following exposure to intimate partner violence when survivors are most receptive for interventions. The confrontation with the trauma of intimate partner violence can, however, affect emergency nurses' ability to engage empathetically with survivors, which is fundamental to all interventions.

Method. A descriptive phenomenological inquiry grounded in Husserlian philosophy was used. The phenomenological reductions were applied throughout data collection and analysis. During 2010 concrete descriptions were obtained from interviewing 11 nurses working in emergency units of two public hospitals in an urban setting in South Africa. In order to arrive at a description of the essence, the data were analysed by searching for the meaning given to the experience of caring for survivors of intimate partner violence.

Findings. Emergency nurses in South Africa are often witnesses of the emotional and physical effects of intimate partner violence. Exposure to the vulnerability and suffering of survivors elicits sympathy and emotional distress. Emergency nurses are left with the emotional impact and disruptive and recurrent memories.

Conclusion. Exploring the tacit internal experiences related to caring for survivors of intimate partner violence revealed emergency nurses' vulnerability to the effects of secondary traumatic stress. The findings generated an opportunity to develop guidelines through which to support and empower emergency nurses.

Keywords: Emergency nursing, descriptive phenomenology, intimate partner violence, secondary traumatic stress, compassion fatigue 


\section{SUMMARY STATEMENT}

\section{What is already known about this topic}

- Survivors of intimate partner violence are often in contact with emergency nurses immediately after the acute violent episode when they are most receptive to interventions.

- Considering the devastating health consequences of intimate partner violence, emergency nurses have a responsibility to identify survivors and intervene appropriately.

- The healthcare system's response towards survivors of intimate partner violence is often inadequate.

- Exposure to the suffering and trauma of intimate partner violence can affect emergency nurses' ability to provide effective care to survivors.

\section{What this paper adds}

- Witnessing the suffering of survivors of intimate partner violence has an emotional impact on emergency nurses and leaves them with disruptive and recurrent memories.

- Exposure to the vulnerability and suffering of survivors elicits emotional distress and feelings of sympathy in emergency nurses.

- Emergency nurses exposed to the consequences of intimate partner violence are at risk of developing secondary traumatic stress.

\section{Implications for practice and/or policy}

- Support programmes with the focus on preventing secondary traumatic stress should be available to emergency nurses often exposed to survivors' experiences with intimate partner violence.

- Support programmes should enhance emergency nurses' awareness of the appropriate use of empathy and focus on emotional regulation, self-awareness and self-care in order to diminish emotional distress when caring for survivors of intimate partner violence. 


\section{INTRODUCTION}

Intimate partner violence (IPV) has reached globally epidemic proportions with a lifetime prevalence of between $15 \%$ and $71 \%$ (Garcia-Moreno et al. 2006). In South Africa prevalence estimates vary (Gass et al. 2010), but a nationally representative study indicated a 19\% lifetime prevalence of IPV (Seedat et al. 2009). Exposure to IPV has devastating physical, psychological and social consequences for women. This is the case especially in South Africa, where 'every six hours a woman is killed by her intimate partner'; a rate six times the global average (Mathews et al. 2004).

For the purpose of this article 'survivors of IPV' refers to women who seek help at an emergency unit for injuries and/or health-related complaints resulting from physical, psychological and/or sexual harm inflicted by an intimate partner. These women are regarded as survivors having the potential to overcome the oppression of IPV.

Since the emergency unit is a common source of contact for survivors of IPV, emergency nurses (ENs) can play a fundamental role in identifying survivors and intervening appropriately (Reisenhofer \& Seibold 2007). Medical interventions, emotional support, safety planning and referral are singled out by the World Health Organization (WHO 2010) as the minimum response that the healthcare system should provide towards survivors of IPV. Support provided in a non-judgmental and empathetic way based on the survivor's needs is crucial in addressing the dynamics of the cycle of violence in which the survivor is caught up (Bostock et al. 2009).

However, the response from the healthcare system is inadequate, as many survivors of IPV are not detected and, even if detected, they are often not managed effectively (Moran 2008, Leppäkoski et al. 2011). Since universal screening for IPV was endorsed by several health professional organizations in the United States of America (USA) (Hien \& Ruglass 2009), much of the research related to the ineffective health system response centred on barriers to screening (Elliot et al. 2002, Heinzer \& Krimm 2002, Ramsden \& Bonner 2002, Anglin \& Sachs 2003, Robinson 2010). The impact of providing care to survivors of IPV as experienced by healthcare professionals (Henderson 2001, Goldblatt 2009), and more specifically by ENs who are often in contact with seriously injured survivors, received less research attention (Sabo 2006). Exposure to seriously violated survivors put ENs at risk for developing secondary traumatic stress, the symptoms of which might affect their ability to provide quality care (Ben-Porat \& Itzhaky 2009, Lester 2010). 
This paper illuminates a phenomenon of global concern: the way ENs and the care they provide can be affected by the invisible and tacit experiences of witnessing the suffering of survivors of IPV. Although explored in the context of two public hospitals in an urban area in South Africa, the essence sets the boundaries that constitute the phenomenon (Giorgi 2009): What in essence make up ENs experiences of witnessing the suffering of survivors of IPV?

\section{BACKGROUND}

Although statistics on the prevalence of IPV survivors treated at emergency units differ, IPV increases the likelihood of non-primary healthcare utilization. It is estimated that in the USA $28 \%$ of women who suffer injuries as a consequence of IPV will receive medical care and in more than $50 \%$ of the cases this care will be given at the emergency unit of a hospital (National Center for Injury Prevention and Control 2003, Lipsky \& Caetano 2007). A Canadian study (MacMillan et al. 2006) reported $11.3 \%$ to $17.7 \%$ twelve-month prevalence rates among patients screened for IPV in two emergency units, while a similar study in Switzerland (Hofner et al. 2005) reported a $11.4 \%$ prevalence rate.

IPV survivors commonly contact the emergency unit immediately after the acute violent episode. During this 'open window period' the survivor is confronted with the reality of the situation and is more receptive to interventions (Curnow 1997, Joyner et al. 2007). ENs are therefore in an ideal position to identify IPV and intervene appropriately to prevent IPVrelated mortality and morbidity (Anglin \& Sachs 2003, Leppäkoski et al. 2011). Comprehensive management of IPV survivors includes early identification, assessment of associated health needs, psychosocial support with the focus on safety, effective referral and provision of appropriate healthcare information (WHO 2010).

In spite of the overwhelming evidence of the negative health consequences associated with IPV (Cherniak et al. 2005, WHO/London School of Hygiene and Tropical Medicine 2010), the healthcare system's response is often inadequate. Critical reviews of the relevant international literature indicate that exposure to IPV is often not detected, and that the majority of women still experience significant challenges to find help (Chuang \& Liebschutz 2002, Reisenhofer \& Seibold 2007). Studies investigating the reasons for the ineffective healthcare system response to IPV identified myths and stereotypes held by healthcare 
professionals, emotional discomfort with IPV, a personal history of IPV and healthcare professionals' inability to address sensitive issues as possible contributing factors (Gadomski et al. 2001, Elliot et al. 2002, Heinzer \& Krimm 2002, Ramsden \& Bonner 2002, Robinson 2010).

In order to identify IPV and intervene at an early stage, universal screening has been endorsed by several health professional organizations in the USA (Hien \& Ruglass 2009). The issue of IPV screening has been researched extensively but the debate for or against screening stays inconclusive because of a lack of evidence regarding effectiveness and improved health outcomes (MacMillan et al. 2009). Liebschutz et al. (2008) suggested that the focus should move away from screening towards empowering IPV survivors through a therapeutic relationship without demanding disclosure. Similarly, survivors expressed the need for sensitive and respectful support by ENs; and viewed building of trust and rapport as more important than disclosure (Watt et al. 2008).

Care provided to a survivor of IPV in a sensitive, empathetic and non-judgmental way fosters a climate that is conducive to disclosure, at the same time communicating respect for the survivor's autonomy (Nelson et al. 2005, Joyner et al. 2007, Moran 2008). Empathetic care, however, requires a level of emotional involvement (Lamm et al. 2007) that can lead to nurses feeling totally overwhelmed, that is according to a study done in Israel on the impact of caring for abused women (Goldblatt 2009). The study illustrates how nurses attempt to block the intense emotions they experience on a professional level from affecting their private lives. The emotional effects of caring for survivors of IPV can in turn play a role in the way in which nurses respond to survivors (Henderson 2001).

In view of the estimated prevalence rates for physical IPV of between $25 \%$ and $55 \%$ (Jewkes \& Morrell 2010), ENs in South Africa are often confronted with the reality of IPV when survivors seek emergency healthcare. Meerkotter (2009) states that survivors of IPV are mostly managed within the framework of a bio-medical approach in South Africa. The same author claims that healthcare professionals seldom enquire about and record the presence of IPV or refer the survivor to support services.

Informal feedback from healthcare professionals working in emergency units and crisis centres in an urban area raised the researcher's awareness of the unique challenges that ENs face when caring for survivors of IPV within the violence-prone South African social 
landscape. Therefore the research on which this paper is based explored and described ENs' experiences of caring for survivors of IPV in an urban South African context.

\section{THE STUDY}

\section{Aim}

The aim of this study was to explore and describe the essence of ENs' experiences of caring for survivors of IPV.

\section{Design}

The research was guided by the philosophical foundations of phenomenology as founded by Husserl (1859-1938). The scientific descriptive phenomenological method, which requires the researcher to 'bracket' all prior knowledge regarding the phenomenon (Giorgi 2009, Holloway \& Wheeler 2010), enabled the researcher to explore the meaning of caring for survivors of IPV within the context of ENs' life-world.

\section{Participants}

The study was conducted among ENs employed at two emergency units situated in an urban area. These ENs are frequently in contact with survivors of IPV as referrals from police, social or legal services; or women who seek help themselves for injuries or health concerns related to IPV. One of the units, at a district public hospital deals with general medical emergencies while the other, at a central public hospital, manages complicated emergencies and deals with seriously injured survivors requiring specialised medical care.

Purposive sampling was used as it is most commonly used in a phenomenological inquiry to select participants that will best help to understand the problem based on their particular knowledge of the phenomenon (Streubert Speziale \& Carpenter 2007). Participants had to have been in contact with survivors of IPV during the course of the year before the commencement of this study to ensure they provided information on experiences within a similar time-frame and context. The sample size of eleven was determined by data saturation, which implies that information from a larger sample size would have been redundant (Polit \& Beck 2008). 


\section{Data collection}

Data was collected using unstructured phenomenological interviews to allow ENs to elaborate on their experiences (Holloway \& Wheeler 2010). An initial broad open-ended question was asked to facilitate the expression of lived experiences without leading the discussion (Streubert Speziale \& Carpenter 2007):

'What is it like for you to provide care to survivors of IPV?'

Interviewing skills such as probing, reflection and paraphrasing were used to indicate understanding of the participants' experiences, which were often of a sensitive and emotional nature. Eleven interviews lasting between 45 and 70 minutes were conducted during December 2010. Interviews were terminated when participants indicated that they had exhausted their descriptions (Streubert Speziale \& Carpenter 2007). Interviews were audio-taped with the participants' permission.

The researcher kept reflective notes during data collection and analysis on personal values and feelings, and areas of possible biasness or role conflict as recommended by Ahern (1999). Field notes were made on interesting observations or findings, for example nonverbal behaviour of participants such as gestures and facial expressions (Polit \& Beck 2008).

\section{Ethical considerations}

The research was approved by the ethics committees of the University of Pretoria and the respective hospitals.

The researcher introduced the study objectives to potential participants during their staff meetings. ENs who had indicated their willingness to participate were seen to obtain informed consent. The researcher explained the purpose and procedures of the study, confidentiality measures and the freedom of choice to withdraw at any time. No attempt was made to convince potential participants who indicated that the study was too sensitive to participate in. Participants who required emotional support were provided with referral options. 


\section{Descriptive analysis}

Descriptive phenomenological analysis was used. The researcher read through the transcribed interviews to obtain a general sense of the whole. The data were divided into meaning units by making an appropriate note in the margin every time a significant shift in meaning was observed. In order to explore the hidden meanings, the data were 'interrogated' (Dahlberg et al. 2008): What was said; how was it said; what are the meanings ENs attach to caring for survivors of IPV? The particular ways in which the experience of providing care to survivors of IPV manifests itself form the constituents of the experience. The essence of the experience was represented on an abstract level, followed by an in-depth description of each constituent that served to further explicate the meaning of the essence. The description reflected all the nuances of the experience of taking care of survivors of IPV quoted in participants' words (Dahlberg et al. 2008).

\section{Rigour}

Two levels of phenomenological reduction were applied - namely the eidetic reduction to ensure scientific rigour and the assumption of the phenomenological attitude, which contributed to a bias-free research process (Wojnar \& Swanson 2007, Giorgi 2009).

The eidetic reduction was applied in order to uncover the essential characteristics of the research phenomenon - that is, to accurately understand the particular way in which ENs experienced the phenomenon of taking care of survivors of IPV and the meanings attached to the experience (Giorgi 2009, Dahlberg et al. 2008).

The researcher maintained the phenomenological attitude through bracketing prior personal knowledge and assumptions about the phenomenon which was explored as it presented itself through the ENs' experiences (Giorgi 2009). An interview with an advanced psychiatric nurse prior to data collection enhanced the researcher's self-awareness of her own preunderstanding of caring for survivors of IPV. The reflective notes helped the researcher to remain open to participants' experiences, comparing them to her own meanings attached to the phenomenon of caring for survivors of IPV. 


\section{Findings}

The nurses interviewed were all in full-time employment at the emergency units of two public hospitals in an urban area in South Africa. Their ages varied between 25 and 50 years. Nine nurses were African, one Caucasian and one coloured. Two of the nurses were male and the rest female.

Evident in the provision of care to survivors of IPV was the experience of witnessing survivors' suffering. The essence of this experience is elucidated by the emotional impact of the witnessing and the subsequent disruptive and recurrent memories. When observing the physical injuries and emotional pain caused by IPV and listening to the narratives of how the violence occurred, ENs experience distressing emotions, which are sometimes similar to what the survivor is feeling. Anger towards the perpetrator and sympathy for the survivor are elicited by scenarios in which the survivor's vulnerability and powerlessness are exposed. Relief is felt when the survivor shows signs of improvement.

The ENs remember what they have witnessed during the survivor's short stay in the emergency unit. The memories can be short lived such as contemplating the day's experiences and feeling concerned about the survivor, but can also linger for longer periods. These memories, which sometimes surface unexpectedly or are triggered by similar occurrences, can be relived as disruptive and vivid mental images, accompanied by strong emotional experiences.

The meaning of the experience - illuminated with excerpts from the interviews - is subsequently discussed under the headings 'emotional impact related to witnessing the effects of IPV' and 'disruptive and recurrent memories':

\section{Emotional impact related to witnessing the effects of IPV}

Witnessing the survivors' suffering has an emotional impact, leading to feelings of depression, sadness, fear, shock, sympathy and anger. The emotional impact can be felt in a sudden, intense way: '...sometimes I used to cry, even when I looked at them...', but can also have a lingering effect and be experienced 'most of the time' 'very deeply'. The disruptive effects of these emotional experiences were described by one participant as 'very much stressing, very much depressing...sometimes I used to cry alone...' The emotional 
impact felt by ENs might even have an effect on their families: '...they are not going to get my full attention I used to give them because I will be sad most of the time...I feel that it's heavy for me...'

On the other hand the realization that a survivor has been helped brings relief, and help ENs to cope with the emotional impact. If the survivor was referred for counselling or has ventilated: '...that heavy load also comes away from you...' A survivor that is 'awake and smiling' and has 'survived' consoles the EN's stress and sadness: '...it makes a lot of difference...I can see that at least what I have done it did make a change...makes me more happy and relieved. Then my stress level is gone...it erased that sadness that was on me...'

ENs cannot look away; they have to face the effects of IPV, no matter how 'bad' it is to 'look at' and 'see' the 'bruises', 'a fracture of the arm', 'the mouth [that] was torn from this part up until here (points to her face), even from the nose...' Witnessing the scars and disfigurement left by IPV is a 'terrible' experience with traumatic effects: '...she was tormented...some abuses...honestly...are very traumatic...'; and: 'I don't know if that was a knife or a panga...cut all over the face...it was not a very nice picture.'

It is especially disturbing to witness the devastating consequences of IPV such as a survivor left with a disability: '...the eye is going to be totally blind. It was very painful for me to see...'; and IPV ending fatally: '...the woman came abused and being beaten almost every day; and that poor lady is bleeding inside...when the patient came in here she dies...it affects me very badly...she's gone in a terrible way...'

It is just as painful to listen to 'stories' of IPV, to be exposed to the 'shocking' details, often revealed for the first time: '...that touches the most is the one who has travelled for some years...if she talks about it, it's very emotional...some things really, you don't expect them, but they do happen...it's like a shock...' Even listening to colleagues sharing their experiences of witnessing can leave ENs with horror: '...she was burned by her boyfriend...it was so horrible... Everybody was talking about it, you could see their faces...it was so painful. I didn't even go to the ward to see the patient...she was burnt over the face...the whole day it was that girl...we kept on asking...how is she doing...?'

ENs are also witnesses to the emotional suffering: '...you just see through their faces they have got that fear...' Observing survivors' emotional pain elicits an emotional response, 
sometimes similar to what the survivor is feeling: '...she was crying hysterically...she does everything that a wife has to do...but she still gets abused...it saddened me...' The emotional burden associated with this phenomenon is evident in the next quotation: 'You feel like crying as well...you can feel this is too much really...you feel what she is feeling...' Sometimes ENs 'go home with that feeling' and 'will be so emotional' about what the survivor endured: '...after she has left it will just kill me alone...'

Witnessing a woman finding herself in a vulnerable and powerless position triggered a feeling of sympathy: 'You feel for the person...she was from another country. She had no one...only that husband who brought her to South Africa to come and abuse her here.' The vulnerability of the survivor is more evident in some scenarios for example a woman with a baby: '...the mother is crying, holding the baby like this (showing how the baby was held), and bruises on the face...' It '...hurts you somewhere...'; '...you just feel sorry for them.' In order to avoid the emotional pain associated with a sympathetic attitude ENs can present with emotional detachment: '...you see things happening and you know: I cannot let it hurt me...' Emotional detachment, however, leaves ENs devoid of feeling and disempowered: '...emotionally we lose touch with the reality of being a human being...it become immoral, people feel heartless...I am a bystander...there's nothing I can do...'

Related to the feeling of sympathy for the woman is the anger towards the perpetrator 'who has done this to his wife or his girlfriend'; the one who 'is victimizing the person.' One participant explained: '...when I look at the man...that hatred and that anger towards that person...'

\section{Recurrent and intrusive memories}

The concern felt for the survivor sometimes stays with ENs like 'something that's pressing on my chest' and when coming on duty the next day 'the first thing that I want to know, I will check where my patient ended'. The concern does not end there, as survivors' stay in the unit is short-lived, leaving ENs with endless unanswered questions: '...is she coping? How is the situation at home...?'; '...what's going to happen...what is she going to do, pack her bags and leave? The boyfriend is he going to say: "I'm sorry?"'; '...she might commit suicide...you don't know what's in her mind...she might think it's over'; and concerns about a survivor's baby: '... what will happen tomorrow; is she going to grow up with both parents...?' 
At times these concerns interrelate with ENs' own experiences. A participant spontaneously shared an experience from her childhood during which she was assaulted and nearly raped but managed to escape. She never told her family as she felt 'responsible for what happened'. Sometimes she is concerned that a survivor is going through a similar experience: '...maybe everybody is blaming her...is she getting that support from the family? ...sometimes people say: "If you listened to us..."'

Disturbing incidents often lingered in the thoughts of participants: 'I can even take a week or two weeks not being myself when I think of that poor lady (who died as a result of her injuries).' Another participant remembered a case in detail after four years: 'It was early morning like this...she even said to me: ".... I always say I am going to pack my bags and leave but this time I seriously mean what I am saying."' She is one of the patients I cannot forget.' This quotation reflects the powerlessness felt by the participant: 'I tried to speak to her: "Wait here until in the morning we will take care of you", but she couldn't...that night going back to that house, what is going to happen...?'

The memories can be of a recurrent and intrusive nature: '...the injuries that I have seen...the moments that I did see the patient...'; 'that vision, it comes back' and: 'The moment you are alone it comes back...' Sometimes the memories are triggered by a similar case: 'When somebody comes beaten up like that I always remember her...'

Some experiences lead to the construction of vivid and intrusive mental images of the IPV as it happened: 'I just visualize that moment when the man was beating her up and begging him to stop...imagine abusing someone who's powerless who doesn't do anything...' The images, sometimes constructed from survivors' narratives as 'they explain to you - this is what happened'; or triggered when witnessing the injuries are visualised in a vivid way: '...what came to my mind: It was like I can just see that girl, somebody pouring the petrol on her like that, and she was screaming...rolling maybe on the ground, burning like that...'

\section{Discussion}

\section{Study limitations}

The interviews required ENs to separate their experiences of being exposed to the consequences of IPV from their daily encounters with patients who were violated and 
traumatized in many ways. It was difficult for some of the participants to make this distinction and they spontaneously revealed other experiences, such as having to deal with survivors of non-partner sexual assault. Since this information was not relevant to this study, it was not taken into consideration during data analysis. This gives rise to certain questions: Can the experience of taking care of survivors of IPV be seen in isolation? Can it be separated from the total experience of being an EN? What constitutes the boundaries of an experience?

Seen within these limitations the study provided but a glimpse of what ENs experience in their daily encounters with survivors of violence and trauma. It is almost impossible to grasp the depth and extent of the feelings and memories they carry around with them after years of witnessing the effects of and listening to stories of violence revealed by healthcare users.

\section{Discussion of findings}

Many experiences constitute witnessing - for example seeing or hearing a direct event of violence taking place, or obtaining knowledge of another person's traumatization (Weingarten 2004a). Caring, associated with close interpersonal involvement, puts nurses in a position where they are witnesses to others' suffering (Ferrell \& Coyle 2008). Similarly ENs have no choice but to expose themselves to IPV survivors' suffering, an experience that inevitably elicits compassion and/or sympathy (Goetz et al. 2010). Expected from nurses, compassionate care requires ENs to enter the survivor's experience (von Dietze \& Orb 2000, Schantz 2007), the sharing of which involves suffering for the other's sake (Nilsson 2011) as seen in ENs' emotional distress.

Compassion and sympathy both emphasize concern for others, but compassion has at its goal the desire to relieve suffering (Goetz et al. 2010). ENs' concerns emerged in their unanswered questions about the fate of the survivor, which also reflected hope that the survivor will be relieved from the suffering of IPV.

Narrations of situations where ENs sensed the vulnerability and powerlessness of a woman reflected a sympathetic rather than empathetic response [the latter is more often associated with a helping relationship (Sabo 2006)]. Sympathy is characterized by feelings of concern and sorrow (Eisenberg \& Eggum 2009), while empathy entails a vicarious sharing of 
another's feelings combined with a cognitive ability to perceive the perspective of the other person (Lamm et al. 2007, de Waal 2008). Serving as a regulatory mechanism to control one's own emotions and prevent emotional overwhelm and burnout (Moriguchi et al. 2007, Gerdes et al. 2010), empathy requires self-awareness and the ability to distinguish between one's own and others' feelings (Decety \& Jackson 2004, Decety \& Lamm 2006).

Empathy without emotional regulation equals emotional contagion and leads to emotional distress (Decety \& Jackson 2004). Also known as empathetic over-arousal, emotional distress results in a desire to relieve one's own suffering, which resembles a focus on one's own needs (Hoffman 2000, Eisenberg \& Eggum 2009). This is opposed to empathy, which has as its goal the enhancement of another's well-being (Batson et al. 2007, Batson 2009). ENs' emotional distress might be related to their capacity for emotional regulation and selfawareness, exposure to extremely painful situations, and a perceived inability to help survivors (Hoffman 2000).

Situations where a person is perceived to be a victim of powers beyond his/her control and of undeserved negative events (such as IPV) evoke sympathetic feelings (Weiner 2006). ENs' sympathetic portrayals of some women stemmed from perceiving them as powerless victims rather than survivors (the latter emphasizes strengths and agency) (Kelly et al. 2011). Sympathy, characterised by emotional affection, is sometimes used in a similar context as pity (von Dietze \& Orb 2000). The emotional distress emanating from feeling sorrow and even fear for the sufferer may result in an emotionally disengaged professional (Boleyn-Fitzgerald 2003). The sufferer, sensing the pitiful confirmation for her state, may feel shamed or paralyzed (Gerdes 2011) and assume the role of a victim (Knapp 2007).

Sympathy not only reflects the 'victim's' unfavourable position, but also the EN in the position of a powerless witness. ENs who are painfully aware of the significance of the survivor's situation, but feel helpless, ineffective, or lack resources to help, are at risk to develop burnout, secondary traumatic stress (STS) and vicarious traumatization (Weingarten 2004b). These concepts as well as compassion fatigue (CF) are used to describe the negative effects that stem from working with traumatized patients (Way et al. 2004).

Figley (1995, p. 7) defined STS as a natural consequence of stress experienced when 'helping or wanting to help a traumatized or suffering person.' As STS is associated with 
caring and compassion 'in the line of duty', Figley (1995, 2002b) suggested the use of the term ' $\mathrm{CF}^{\prime}$ that also depicts the depletion of the professional's ability to feel and care for others (Mc Holm 2006) and bear their suffering (Figley 2002a). Although empathy is associated with CF Figley (1995) and Gerdes (2011) proposed that professionals who feel mainly sympathy might be more prone to emotional exhaustion as they tend to take on others' burdens; a process that impedes the therapeutic process (Clark 2010). This is opposed to the therapeutic effects of empathy that allows for a compassionate response (Decety \& Jackson 2004) and facilitates emotional expression (Wesby et al. 2012). The positive effects of empathy on professionals as proposed by Gerdes (2011) are evident in ENs' relief when survivors ventilated their experiences.

The symptoms of STS, which are almost the same as those of post-traumatic stress disorder (Figley 2002a), seem to accurately capture the recurrent and intrusive memories (also called flashbacks) and emotional distress experienced by ENs. STS presents itself as a preoccupation with others' traumatic experiences by re-experiencing the events, avoiding or numbing of reminders of the event and/or persistent arousal (Figley 2002a, McHolm 2006). Some of the scenarios witnessed, or mental images constructed from survivors' experiences become entrenched in ENs' memories. The memories, accompanied by intense emotional distress, sometimes surface spontaneously or are triggered by similar experiences.

\section{Relevance to clinical practice}

The study clearly indicates a need for interventions to support ENs in their work with IPV survivors. Forthcoming from the study guidelines for supervision, training programmes to develop skills and knowledge, emotional support, and organisational support structures could be developed to improve the clinical practice situation for ENs; improve the care provided to survivors; and prevent the consequences of STS (Bell 2003, Linley \& Joseph 2007, Aycock \& Boyle 2009). Such interventions should be based on the following principles: the acknowledgement of the existence and consequences of STS; encouragement to share and express emotional experiences (Figley 2002a, 2002b); ways to distinguish between empathy and sympathy in the nurse-patient relationship to enhance ENs awareness of the appropriate use of empathy (Clark 2010); and emotional regulation and self-awareness to diminish emotional distress (Gerdes et al. 2010). McHolm (2006) and Showalter (2010) provide guidelines for self-care and self-reflection and ways to restore professional and personal balance. 


\section{Conclusion}

The phenomenological description gave ENs a voice: this is what it is like to provide care to survivors of IPV in a country where violence is such a common occurrence that the terrible injuries witnessed just become part of another day's work. However, the day's witnessing does not pass lightly; it leaves ENs with concerns, emotional distress and a burden of memories.

The findings explicated ENs' vulnerability to develop STS and other consequences of vicarious trauma. Quantitative studies using standardised measurement tools are recommended to determine the extent to which ENs are at risk. Scales to measure sympathy/ empathy/ compassion in ENs might also assist with the development and design of supervision and training programmes to support ENs towards providing empathetic care to survivors of IPV. Other aspects to consider would be the strength of current employee wellness programmes available to ENs, the development of a peer- and multi-disciplinary support system and policy revision to provide for supervision and debriefing programmes. Based on the findings and the available literature, guidelines to support ENs on an individual, group and organisation level will be developed.

\section{REFERENCES}

Ahern K.J. (1999) Ten tips for reflexive bracketing. Qualitative Health Research 9(3), 407411.

Anglin D. \& Sachs C. (2003) Preventive care in the emergency department: screening for domestic violence in the emergency department. Academic Emergency Medicine 10(10), 1118-1127.

Aycock N. \& Boyle D. (2009) Interventions to manage compassion fatigue in oncology nursing. Clinical Journal of Oncology Nursing 13(2), 183-191.

Batson C.D., Eklund J.H., Chermok V.L., Hoyt J.L. \& Ortiz B.G. (2007) An additional antecedent of empathic concern: valuing the welfare of the person in need. Journal of Personality and Social Psychology 93(1), 65-74.

Batson C.D. (2009) These things called empathy: eight related but distinct phenomena. In The Social Neuroscience of Empathy (Decety J. \& Ickes W., eds.), The MIT Press, Cambridge MA, pp. 3-15.

Bell H. (2003) Strengths and secondary trauma in family violence work. Social Work 48(4), 513-522. 
Ben-Porat A. \& Itzhaky H. (2009) Implications of treating family violence for the therapist: secondary traumatization, vicarious traumatization, and growth. Journal of Family Violence 24(7), 507-515.

Boleyn-Fitzgerald P. (2003) Care and the problem of pity. Bioethics 17(1), 1-20.

Bostock J., Plumpton M. \& Pratt R. (2009) Domestic violence against women: understanding social processes and women's experiences. Journal of Community \& Applied Social Psychology 19(2), 95-110.

Cherniak D., Grant L., Mason R., Moore B. \& Pellizzari R. (2005) Intimate partner violence consensus statement. Journal of Obstetrics and Gynaecology Canada 27(4), 365-418.

Chuang C.H. \& Liebschutz J.M. (2002) Screening for intimate partner violence in the primary care setting: a critical review. Journal of Clinical Outcomes Management 9(10), 565571.

Clark A.J. (2010) Empathy and sympathy: therapeutic distinctions in counseling. Journal of Mental Health Counseling 32(2), 95-101.

Curnow S.A.M. (1997) The open window phase: helpseeking and reality behaviors by battered women. Applied Nursing Research 10(3), 128-135.

De Waal F.B.M. (2008) Putting the altruism back into altruism: the evolution of empathy. Annual Review of Psychology 59, 279-300.

Dahlberg K., Dahlberg H. \& Nyström M. (2008) Reflective Lifeworld Research. Studentlitteratur, Lund.

Decety J. \& Jackson P.L. (2004) The functional architecture of human empathy. Behavioral and Cognitive Neuroscience Reviews 3(2), 71-100.

Decety J. \& Lamm C. (2006) Human empathy through the lens of social neuroscience. Scientific World Journal 6, 1146-1163.

Eisenberg N. \& Eggum N.D. (2009) Empathetic responding: sympathy and personal distress. In The Social Neuroscience of Empathy (Decety J. \& Ickes W., eds.), The MIT Press, Cambridge MA, pp. 71-83.

Elliott L., Nerney M., Jones T. \& Friedmann P.D. (2002) Barriers to screening for domestic violence. Journal of General Internal Medicine 17(2), 112-116.

Ferrell B.R. \& Coyle N. (2008) The nature of suffering and the goals of nursing. Oncology Nursing Forum 35(2), 241-247.

Figley C.R. (1995) Compassion fatigue as secondary traumatic stress disorder: an overview. In Compassion fatigue: Coping with Secondary Traumatic Stress Disorder in Those Who Treat the Traumatized (Figley C.R.), Brunner/ Mazel, New York, pp. 1-17.

Figley C.R. (2002a) Compassion fatigue: psychotherapists' chronic lack of self care. Journal of Clinical Psychology 58(11), 1433-1441. 
Figley C.R. (2002b) Treating Compassion Fatigue. Brunner-Routledge, New York.

Gadomski A.M., Wolff D., Tripp M., Lewis C. \& Short L.M. (2001) Changes in health care providers' knowledge, attitudes, beliefs, and behaviors regarding domestic violence, following a multifaceted intervention. Academic Medicine 76(10), 1045-1052.

Garcia-Moreno C., Jansen H.A.F.M., Ellsberg M., Heise L. \& Watts C.H. (2006) Prevalence of intimate partner violence: findings from the WHO multi-country study on women's health and domestic violence. Lancet 368(9543), 1260-1269.

Gass J.D., Stein D.J., Williams D.R. \& Seedat S. (2010) Intimate partner violence, health behaviours, and chronic physical illness among South African women. South African Medical Journal 100(9), 582-585.

Gerdes K.E. (2011) Empathy, sympathy, and pity: 21st-century definitions and implications for practice and research. Journal of Social Service Research 37(3), 230-241.

Gerdes K.E., Segal E.A. \& Lietz C.A. (2010) Conceptualising and measuring empathy. The British Journal of Social Work 40(7), 2326-2343.

Giorgi A. (2009) The Descriptive Phenomenological Method in Psychology: A Modified Husserlian Approach. Duquesne University Press, Pennsylvania.

Goetz J.L., Keltner D. \& Simon-Thomas E. (2010) Compassion: an evolutionary analysis and empirical review. Psychological Bulletin 136(3), 351-374.

Goldblatt H. (2009) Caring for abused women: impact on nurses' professional and personal life experiences. Journal of Advanced Nursing 65(8), 1645-1654.

Heinzer M. \& Krimm J.R. (2002) Barriers to screening for domestic violence in an emergency department. Holistic Nursing Practice 16(3), 24-33.

Henderson A. (2001) Factors influencing nurses' responses to abused women: what they say they do and why they say they do it. Journal of Interpersonal Violence 16(12), 1284-1306.

Hien D. \& Ruglass L. (2009) Interpersonal partner violence and women in the United States: an overview of prevalence rates, psychiatric correlates and consequences and barriers to help seeking. International Journal of Law and Psychiatry 32(1), 48-55.

Hoffman M. (2000) Empathy and Moral Development. Implications for Caring and Justice. Cambridge University Press, Cambridge.

Hofner M., Python N.V., Martin E., Gervasoni J., Graz B. \& Yersin B. (2005) Prevalence of victims of violence admitted to an emergency department. Emergency Medicine Journal 22(7), 481-485.

Holloway I. \& Wheeler S. (2010) Qualitative Research in Nursing and Healthcare, $3^{\text {rd }}$ edn. Wiley-Blackwell, Oxford, United Kingdom. 
Jewkes R. \& Morrell R. (2010) Gender and sexuality: emerging perspectives from the heterosexual epidemic in South Africa and implications for HIV risk and prevention. Journal of the International Aids Society 13(1), 6-6.

Joyner K., Theunissen L., De Villiers L., Suliman S., Hardcastle T. \& Seedat S. (2007) Emergency care provision for, and psychological distress in, survivors of domestic violence. South African Family Practice 49(3), 15.

Kelly U.A., Gonzalez-Guarda R.M. \& Taylor J. (2010) Theories of intimate partner violence. In Family Violence and Nursing Practice (Humphreys J. \& Campbell J.C., eds.), Springer Publishing Company, New York, pp. 51-90.

Knapp H. (2007) Therapeutic Communication: Developing Professional Skills. Sage Publications, Inc, Thousand Oaks, CA.

Lamm C., Batson C.D. \& Decety J. (2007) The neural substrate of human empathy: effects of perspective-taking and cognitive appraisal. Journal of Cognitive Neuroscience 19(1), 42-58.

Leppäkoski T., Paavilainen E. \& Astedt-Kurki P. (2011) Experiences of emergency care by the women exposed to acute physical intimate partner violence from the Finnish perspective. International Emergency Nursing 19(1), 27-36.

Lester N. (2010) Compassion fatigue. Mental Health Practice 14(2), 11-11.

Liebschutz J., Battaglia T., Finley E. \& Averbuch T. (2008) Disclosing intimate partner violence to health care clinicians - what a difference the setting makes: a qualitative study. BMC Public Health 8(1), 229.

Linley P.A. \& Joseph S. (2007) Therapy work and therapists' positive and negative wellbeing. Journal of Social and Clinical Psychology 26(3), 385-403.

Lipsky S. \& Caetano P. (2007) The role of race/ethnicity in the relationship between emergency department use and intimate partner violence: findings from the 2002 National Survey on Drug Use and Health. American Journal of Public Health 97(12), 2246-2252.

MacMillan H.L., Wathen C.N., Jamieson E., Boyle M.H., Shannon H.S., Ford-Gilboe M., Worster A., Lent B., Coben J.H., Campbell J.C. \& McNutt L.A. (2009) Screening for intimate partner violence in health care settings: a randomized trial. JAMA: Journal of the American Medical Association 302(5), 493-501.

MacMillan H.L., Wathen C.N., Jamieson E., Boyle M., McNutt L., Worster A., Lent B. \& Webb M. (2006) Approaches to screening for intimate partner violence in health care settings: a randomized trial. JAMA: Journal of the American Medical Association 296(5), 530536.

Mathews S., Abrahams N., Martin L.J., Vetten L., van der Merwe L. \& Jewkes R. (2004) Every six hours a woman is killed by her intimate partner: a national study of female homicide in South Africa. Medical Research Council Policy brief 5. Retrieved from http://www.mrc.ac.za/policybriefs/woman.pdf on 4 March 2010. 
McHolm F. (2006) Rx for compassion fatigue. Journal of Christian Nursing 23(4), 12.

Meerkotter A. (2009) Domestic violence, health and HIV. A review on progress made in addressing domestic violence through the HIV \& AIDS and STI National Strategic Plan 2007-2011. Tshwaranang Legal Advocacy Centre to End Violence Against Women (TLAC) Policy brief 3. Retrieved from http://www.healthlink.org.za/uploads/files/PolicyBriefNSP LR.pdf on 4 April 2010

Mick J. (2006) Identifying signs and symptoms of intimate partner violence in an oncology setting. Clinical Journal of Oncology Nursing 10(4), 509-513.

Moran B.A. (2008) Intimate partner violence: the difference nurses can make. Nursing for Women's Health 12(3), 194-196.

Moriguchi Y., Decety J., Ohnishi T., Maeda M., Mori T., Nemoto K., Matsuda H. \& Komaki G. (2007) Empathy and judging other's pain: an fMRI study of alexithymia. Cerebral Cortex 17(9), 2223-2234.

National Center for Injury Prevention and Control (US) (2003) Costs of Intimate Partner Violence against Women in the United States. Centers for Disease Control and Prevention, Atlanta (GA). Retrieved from http://www.cdc.gov/violenceprevention/pdf/IPVBook-a.pdf on 20 April 2011.

Nelson J.C., Adrine R.B., Alpert E. \& Buel S. (2005) Domestic violence in the adult years. Journal of Law Medicine \& Ethics 33(4Suppl), 28-33.

Nilsson P. (2011) On the suffering of compassion. Philosophia, 39(1), 125-144.

Polit D.F. \& Beck C.T. (2008) Nursing Research: Generating and Assessing Evidence for Nursing Practice. Lippincott Williams \& Wilkins, Philadelphia.

Ramsden C. \& Bonner M. (2002) A realistic view of domestic violence screening in an emergency department. Accident and Emergency Nursing 10(1), 31-39.

Reisenhofer S. \& Seibold C. (2007) Emergency department care of women experiencing intimate partner violence: are we doing all we can? Contemporary Nurse: A Journal for the Australian Nursing Profession 24(1), 3-14.

Robinson R. (2010) Myths and stereotypes: how registered nurses screen for intimate partner violence. JEN: Journal of Emergency Nursing 36(6), 572-576.

Sabo B.M. (2006) Compassion fatigue and nursing work: can we accurately capture the consequences of caring work? International Journal of Nursing Practice 12(3), 136-142.

Schantz M.L. (2007) Compassion: a concept analysis. Nursing Forum 42(2), 48-55.

Seedat M., Van Niekerk A., Jewkes R., Suffla S. \& Ratele K. (2009) Violence and injuries in South Africa: prioritising an agenda for prevention. The Lancet 374(9694), 1011-1022. 
Showalter S.E. (2010) Compassion fatigue: what is it? Why does it matter? Recognizing the symptoms, acknowledging the impact, developing the tools to prevent compassion fatigue, and strengthen the professional already suffering from the effects. The American Journal of Hospice \& Palliative Care 27(4), 239-242.

Streubert Speziale H.J. \& Carpenter D.R. (2007) Qualitative Research in Nursing: Advancing the Humanistic Imperative, $4^{\text {th }}$ edn. Lippincott Williams \& Wilkins, Philadelphia, PA.

Von Dietze E. \& Orb A. (2000) Compassionate care: a moral dimension of nursing. Nursing Inquiry 7(3), 166-174.

Watt M.H., Bobrow E.A. \& Moracco K.E. (2008) Providing support to IPV victims in the emergency department: vignette-based interviews with IPV survivors and emergency department nurses. Violence against Women 14(6), 715-726.

Way I., Van Deusen K.M., Martin G., Applegate B. \& Jandle D. (2004) Vicarious trauma. Journal of Interpersonal Violence 19(1), 49-71.

Weiner B. (2006) Social Motivation, Justice, and the Moral Emotions: An Attributional Approach. Lawrence Erlbaum Associates, Inc, New Jersey.

Weingarten K. (2004a) Witnessing the effects of political violence in families: mechanisms of intergenerational transmission and clinical interventions. Journal of Marital and Family Therapy 30(1), 45-59.

Weingarten K. (2004b) Common shock: witnessing violence in clients' lives. Counselor, the Magazine for Addiction Professionals 5(1), 70-74.

Wesby R., Coll X. \& Tarbuck A. (2012) Dealing with emotions. In Communication Skills in Mental Health Care: An Introduction (Coll X., Papageorgiou A., Stanley A. \& Tarbuck A., eds.), Radcliffe Pub, London, pp. 96-108.

Wojnar D.M. \& Swanson K.M. (2007) Phenomenology. Journal of Holistic Nursing 25(3), 172-180.

World Health Organization (2010) Expert meeting on Health-sector Responses to Violence Against Women, 17-19 March 2009, Geneva, Switzerland. World Health Organization, Geneva, Switzerland. Retrieved from http://whqlibdoc.who.int/publications/2010/9789241500630 eng.pdf on 8 August 2011.

World Health Organization/ London School of Hygiene and Tropical Medicine (2010) Preventing Intimate Partner and Sexual Violence against Women: Taking Action and Generating Evidence. World Health Organization, Geneva, Switzerland. 